\title{
Conservative Management of Inferior Vena Cava Cement Spike After Percutaneous Vertebroplasty Causes Fatal Cardiac Tamponade
}

VICTOR LEE, MRCP; RIYAZ PATEL, MD, MRCP; PASCAL MEIER, MD; DAVID LAWRENCE, FRCS; NEIL ROBERTS, FRCS, The Heart Hospital, University College London Hospital NHS Foundation Trust, London, UK. Address correspondence to Dr. Lee, The Heart Hospital, University College London Hospital NHS Foundation Trust, 16-18 Westmoreland Street, London W1G 8PH, UK. E-mail: victorkflee@ hotmail.com. J Rheumatol 2014;41:141-2; doi:10.3899/jrheum.130570

Percutaneous vertebroplasty with polymethyl methacrylate (PMMA) has now emerged as a standard treatment for osteoporotic fracture. Cement extravasation into inferior vena cava (IVC) is a potential complication. We describe a case where conservative management of IVC cement fragment led to fatal cardiac tamponade despite surgical repair.

A patient underwent L3 percutaneous vertebroplasty with PMMA for osteoporotic fracture, which was complicated by cement extravasation. Computed tomography (CT) showed a linear opacity within IVC (Figure 1). The patient was treated conservatively because she was asymptomatic.
Three months later, breathlessness ensued. CT pulmonary angiogram ruled out pulmonary embolus. Abdominal ultrasound showed absence of IVC fragment, suggesting cement migration. Echocardiogram showed a $1.5 \mathrm{~cm}$ global pericardial effusion causing tamponade with a long thin spike piercing the right ventricle (Figure 2). She was treated with emergency pericardiocentesis and emergency cardiac surgery. The spike was removed and the RV puncture site was repaired (Figure 3). The patient developed acute respiratory distress syndrome postoperatively and died 5 days after admission.

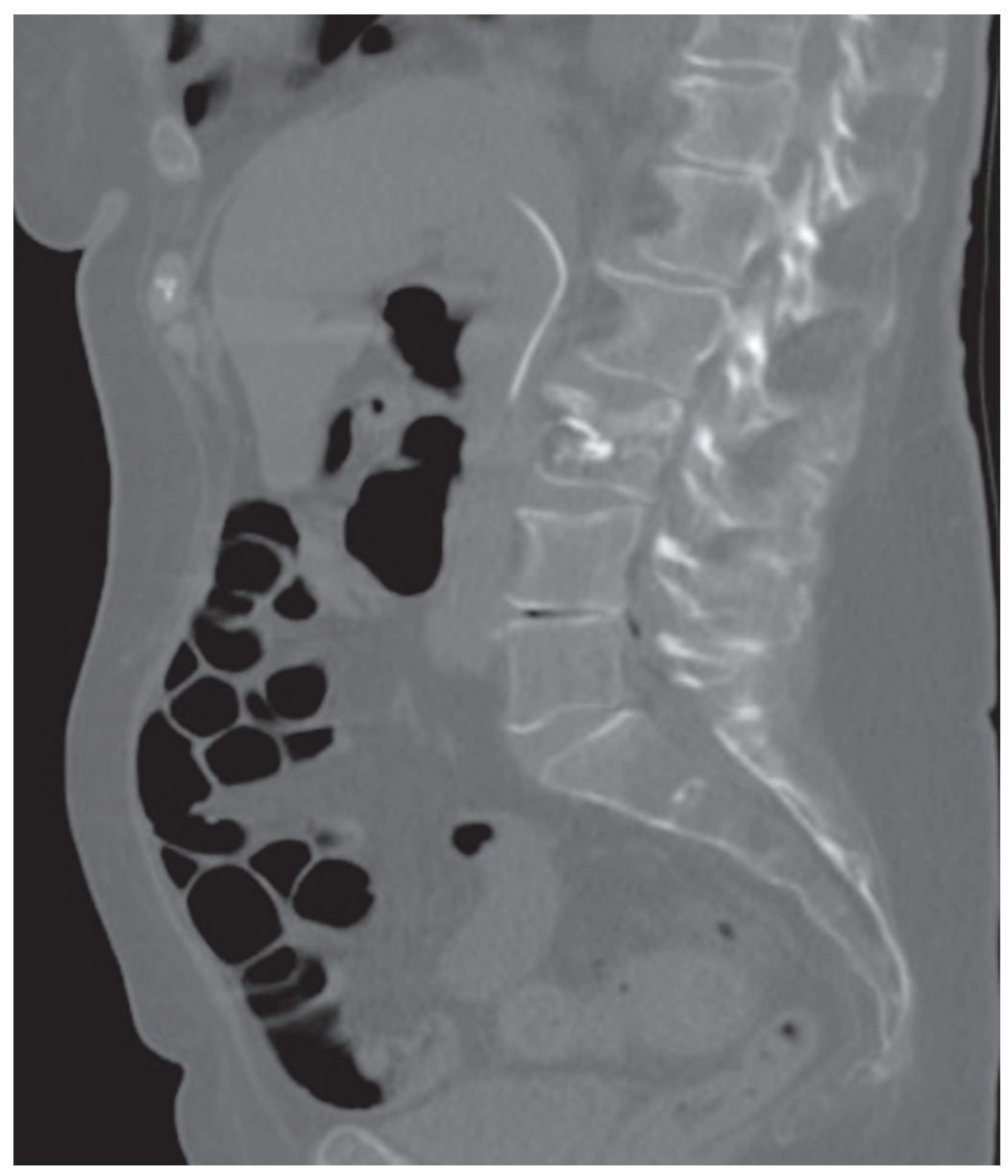

Figure 1. Computed tomography of abdomen showing the inferior vena cava cement spike.

Personal non-commercial use only. The Journal of Rheumatology Copyright @ 2014 . All rights reserved. 


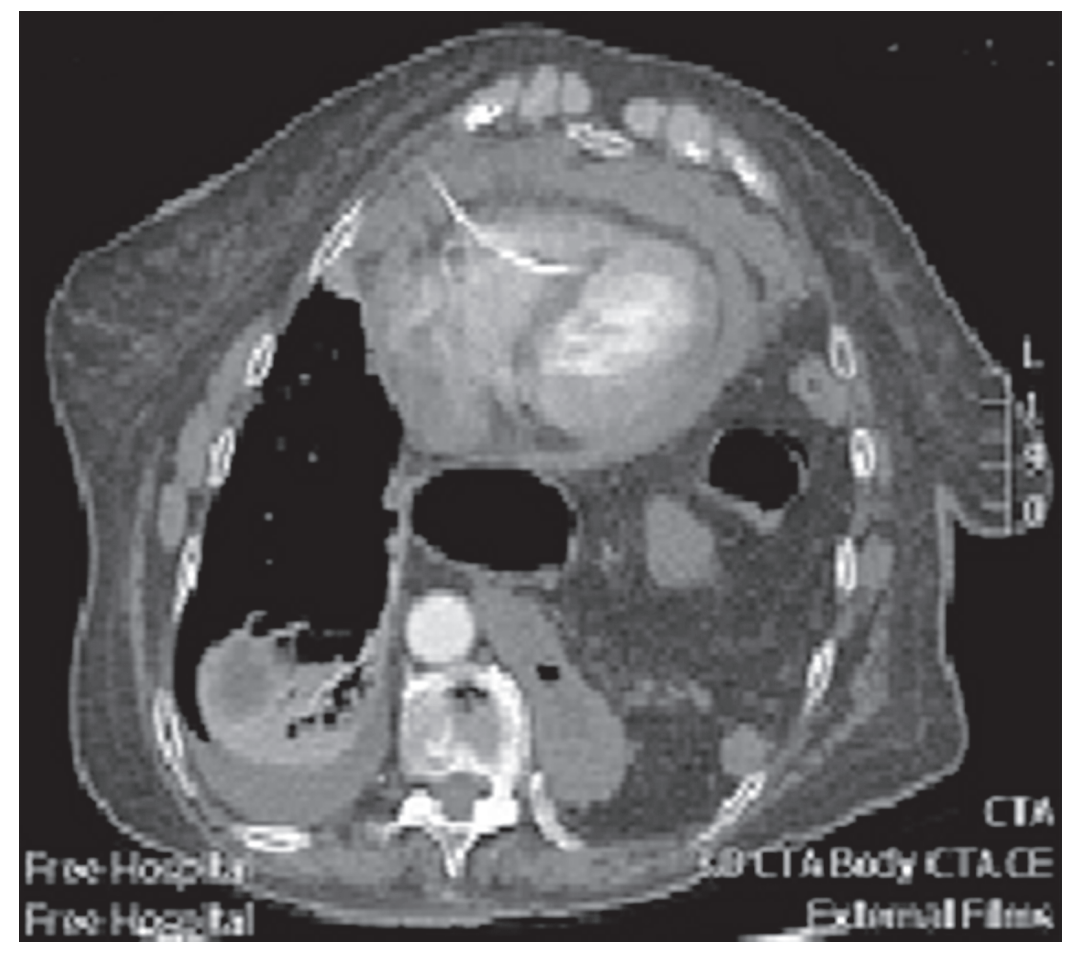

Figure 2. Computed tomography of the chest showing the embolized cement spike perforating the right ventricle, causing tamponade.

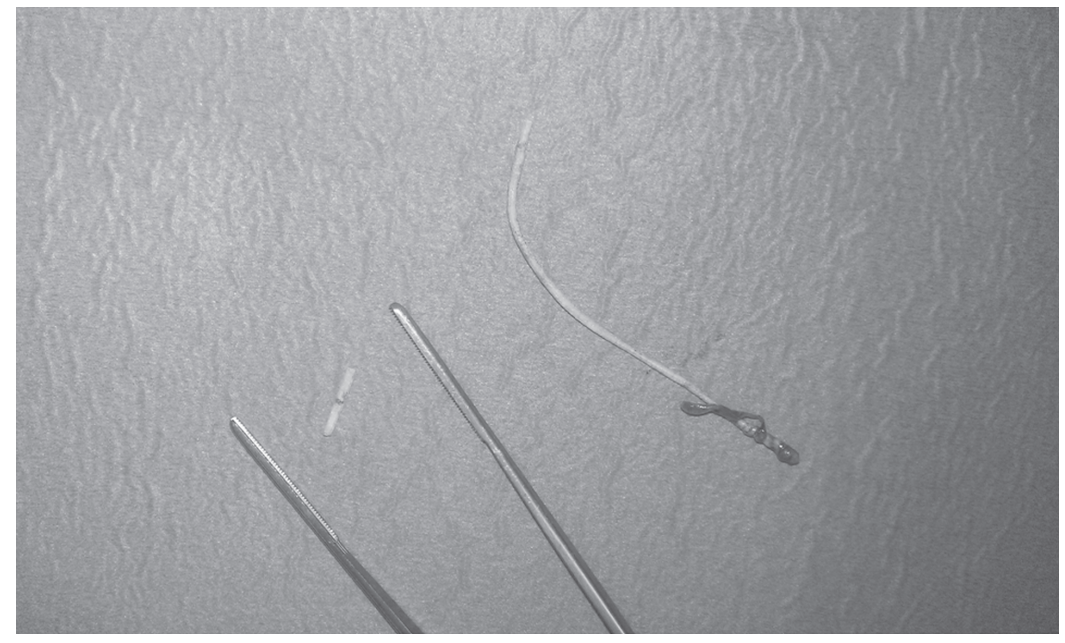

Figure 3. Cement spikes removed by cardiac surgery.

The management of IVC cement post-vertebroplasty is a subject of debate. Many recommend surgical removal, but some groups report good patient outcome with conservative management ${ }^{1,2}$. This case demonstrates that the watch-and-wait policy for IVC cement spikes post-percutaneous vertebroplasty cannot be recommended because of the risk of fatal cardiac tamponade.

\section{REFERENCES}

1. Biega TJ, Lettieri CJ, Levy LM, Venbrux AC. Linear pulmonary opacities in an asymptomatic patient. Respiration 2006;73:705-7.

2. Kao KC, Tu YK, Lai PL. Inferior vena cava syndrome following percutaneous vertebroplasty with polymethylmethacrylate. Spine 2008;33:E329-33 